\title{
EL TRATAMIENTO DE LA HIPNOSIS EN LA TRILOGÍA HIPNÓTICA (1984-1991) DE LARS VON TRIER
}

\section{Antonio Díaz Lucena}

\section{RESUMEN}

Lars von Trier dirigió entre 1984 y 1991 su primera Trilogía. El trance hipnótico es el nexo en común de los tres filmes, aunque se despliega de forma diferente en cada uno de ellos. Nos preguntamos en este artículo por la relación del cineasta con esta técnica. Asimismo, indagamos en la posible significación que pudiera tener. Con este fin, profundizamos en el estilo y concepción artística de uno de los directores daneses más conocidos que también aplicó el trance hipnótico en su cinematografía: Carl Th. Dreyer. En este proceso, nos daremos cuenta de la cercanía de ambos cineastas con los preceptos del Romanticismo y su búsqueda personal de la esencia del ser humano.

\section{SUMMARY}

Lars von Trier directed his first Trilogy between 1984 and 1991. The hypnotic trance is the nexus in common for the three films, although it is deployed in a different way in each one. We ask ourselves in this article about the relationship of the film maker with this technique. Likewise, we investigate the possible significance that it could have. To this end, we delve into the style and artistic conception of one of the most well known Danish directors who also applied the hypnotic trance in his cinematography, Carl Th. Dreyer. During this process, we realise the closeness of both film makers with the precepts of Romanticism and their personal search of the essence of the human being.

\section{Introducción}

Creo que la hipnosis es extremadamente excitante y el cine en sí mismo es un medio con un efecto hipnótico ${ }^{1}$.

El trance hipnótico desde sus orígenes ha inspirado muchas tramas narrativas tanto en cine como literatura, especialmente en el periodo que abarca entre 1919 y 1929. En plena ebullición del Expresionismo alemán la utilización de la hipnosis fue recurrente en muchos de los relatos cinematográficos; ya sea por su relación originaria con el oscurantismo o la taumaturgia, o como técnica psicoanalítica para escarbar en la memoria de un paciente. Ejemplo de ello lo hallamos en filmes, como: Nosferatu - eine Symphonie des Grauens (Nosferatu, F. W. Murnau, 1922), Der Golem, wie er in die Welt kam (El Golem, Paul Wegener y Carl Boese, 1920), Schatten - Eine nächtliche Halluzination (Sombras, Arthur Robison, 1923) de, Das

\footnotetext{
${ }^{1}$ Björkman, Stig (1999): Trier on von Trier. Ed. Faber and Faber Limited, London, 2003, p. 71.
} 
Wachsfigurenkabinett (El hombre de las figuras de cera, Paul Leni, 1924) o Metropolis (Metrópolis, Fritz Lang, 1927). Posteriormente a la vorágine del Expresionismo alemán, directores como Carl Th. Dreyer o Werner Herzog experimentaron con ello en el propio set de rodaje. Concretamente Dreyer, a través de esta técnica, intentó dotar de un nuevo interiorismo dramático a la actuación de sus protagonistas. El resultado obtenido en su largometraje Gertrud (1964) ha sido uno de los casos más deslumbrantes en la Historia del Cine. Varias secuencias de Gertrud nos conducen a pensar en un film protagonizado por espectros.
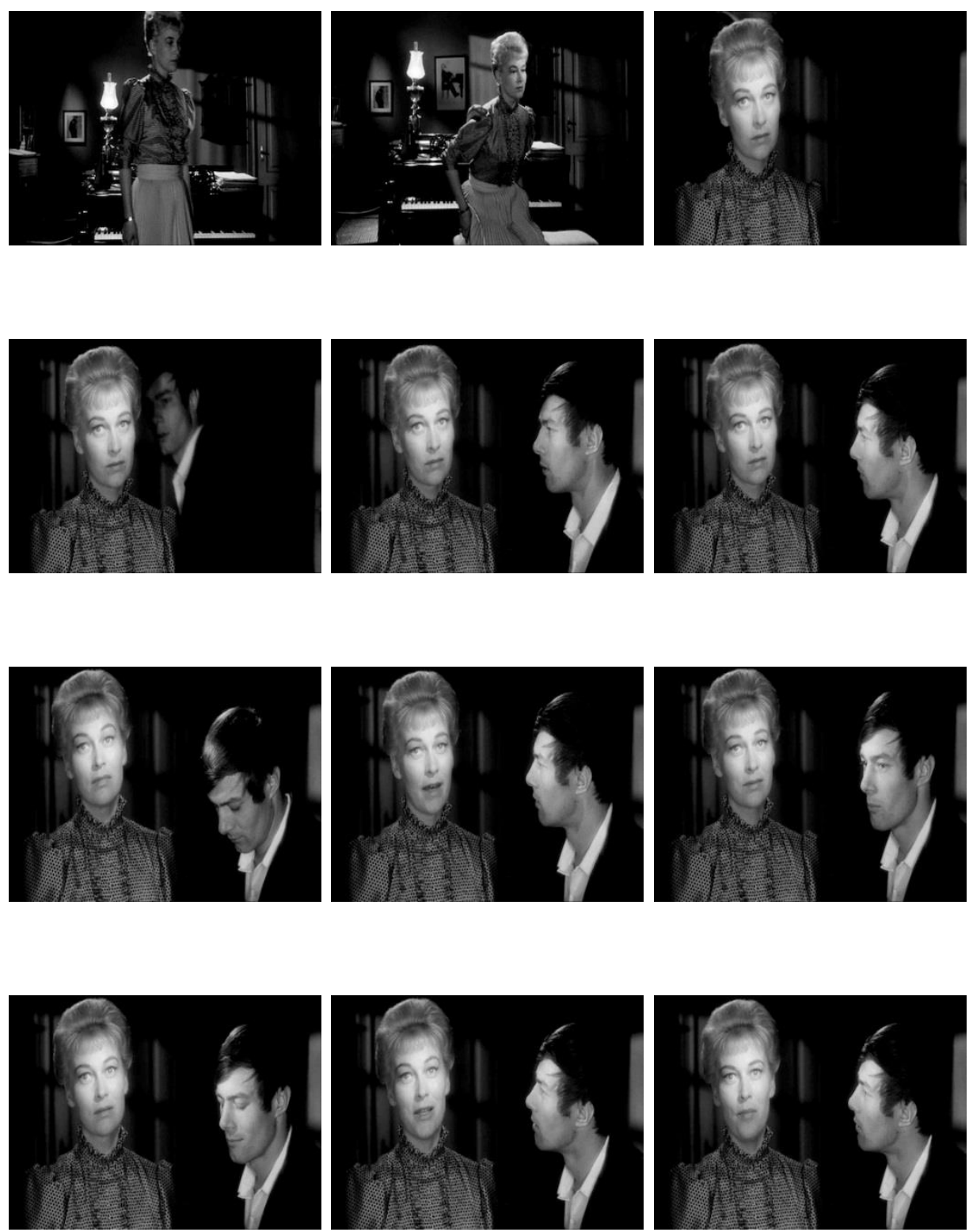

(Imágenes del film Gertrud²)

\footnotetext{
${ }^{2}$ Timecode: 00:30:32
} 
En esta secuencia apreciamos cómo Gertrud (Nina Pens Rode) se sienta en el taburete del piano. Junto a ella aparece Gabriel (Ebbe Rode). Él le pregunta quién es realmente y ella le responde que muchas cosas. El plano elegido parece describirnos una confesión bajo la influencia del trance hipnótico. Dreyer consiguió con ello una bella metáfora sobre la alienación de una mujer moderna en una sociedad danesa todavía no preparada para aceptar con normalidad conductas femeninas independientes y autónomas.

Lars von Trier ha declarado en varias ocasiones que este film de Dreyer fue el que más le ha influenciado ${ }^{3}$ de su filmografía. Podríamos incluso llegar a pensar que aquí se halla la raíz de su familiaridad con el método hipnótico y su aplicación cinematográfica.

\section{Carl Theodor Dreyer y el trance hipnótico}

Yo diría que no me siento tan inspirado por Dreyer como me inspira su manera de dirigir ${ }^{4}$.

Lars von Trier

Después de la realización para televisión del guion escrito por Dreyer sobre la tragedia Medea (1998), Lars von Trier declaró que se sintió en constante contacto espiritual con él ${ }^{5}$. Los dos directores comparten rasgos comunes y el más visible pudiera pensarse que anida en la incomprensión de su obra en su tierra natal, Dinamarca. En el caso de Dreyer, tanto Vampyr (La bruja vampiro, 1932), Vredens Dag (Dies Irae, 1943), o su última película Gertrud (1964) y -ésta última a pesar de haber sido filmada íntegramente en Dinamarca-, fueron todas un fracaso comercial. Lars von Trier fue consciente de que el fiasco de Gertrud fue un grandísimo revés para Dreyer debido principalmente a la gran cantidad de críticas ${ }^{6}$ que recibió en Dinamarca.

Si nos adentramos en la forma que tenía Dreyer de concebir la creación cinematográfica, podríamos enunciar que utiliza un estilo organicista ${ }^{7}$. Entendía el proceso creativo como una forma de dar vida dispensando a la obra de arte de personalidad y alma, siempre a través del estilo ${ }^{8}$. Concedió una importancia vital al estilo del artista que es - según él- la vía de la que dispone el cineasta para expresar su percepción de la materia ${ }^{9}$. De esta manera, encontró en su principio de abstracción una forma innovadora para elevarse desde la realidad. Lo definió de la siguiente manera:

En lo que a mí respecta, solo veo un camino: la abstracción. Y para no ser mal entendido, me apresuro a definir la palabra

\footnotetext{
${ }^{3}$ Björkman, Stig y Nyman, Lena (1995): «I Am Curious, Film: Lars von Trier». En Lumholdt, Jan (Ed.) Lars von Trier Interviews. Ed. The University Press of Missisippi, 2003, p. 101.

${ }^{4}$ Ibid., p. 101.

${ }^{5}$ Stevenson, Jack (2002): Lars von Trier. Ed. Paidós, Barcelona, 2005, p. 43.

${ }^{6}$ Björkman, Stig y Nyman, Lena (1995): op. cit., p. 101.

${ }^{7}$ Monty, Ib (1964): Carl Th. Dreyer. Sobre el cine. Ed. Gráficas San Martín, Valladolid, 1995, p. 107.

${ }^{8}$ Ibid., p. 108.

${ }^{9}$ Ibid., p. 108.
} 


\begin{abstract}
abstracción como el concepto creativo que exige que el artista se eleve a partir de la realidad, para reforzar su contenido espiritual, que puede ser psicológico o puramente estético. Dicho con brevedad: el arte debe de representar la vida interior y no la exterior ${ }^{10}$.
\end{abstract}

Dreyer propone la integración de elementos con el fin de formar un todo orgánico, vivo, capaz de representar «la vida interior y no la exterior» ${ }^{11}$. A la luz de esta idea, pudiéramos pensar que el uso que hace Dreyer del trance hipnótico tiene como fin dar forma a su concepto de creación organicista mediante la representación de la vida interior de sus actores. Dicho de otra manera, el trance hipnótico parece ayudarle a llegar a la verdad y la pureza del sujeto; plasmar un elemento irreductible del actor: su esencia. De igual manera, pudiéramos también pensar que Lars von Trier busca una libertad parecida en el individuo en tanto que desea que el hombre se muestre tal y como es: sin máscaras. La diferencia entre los dos pudiera hallarse en el fin de la liberación del individuo que los dos sostienen.

\title{
El concepto de abstracción de Dreyer: influencia visual en Lars von Trier.
}

A priori, se antoja ardua la tarea de reconocer la influencia visual de Dreyer en los trabajos de Lars von Trier, pero si nos fijamos en el ritmo y la cadencia de las imágenes, podríamos pensar en una posible conexión entre los dos directores daneses. El recurso visual de ralentizar imágenes en los films de Lars von Trier se ha configurado como una marca de su estilo, especialmente en su ópera prima: Forbrydelsens Element. Esta técnica concede a su obra un aurea de reflexión y profundidad. Si a esto le sumamos que la trama del largometraje escenifica un viaje hacia el inconsciente del protagonista, tropezamos con la necesidad de tener que inventar un tempo imaginario con un ritmo que pretende recrear el interior de nuestra mente: la representación del inconsciente.

Con gran perseverancia, Dreyer ha hecho hincapié en la obligación que tiene el cine de escapar de la naturalidad que proporciona la mimesis de la realidad: "Hasta que el cine no se eleve, no tendrá la posibilidad de llegar a la altura de la imaginación. Por tanto, debemos arrancar al cine de las garras del naturalismo» ${ }^{12}$. Parte de este pensamiento sigue una línea romántica si tenemos en cuenta la importancia que deposita el cineasta en la imaginación como elemento para unir contrarios. Durante el periodo romántico, la comunicación entre la consciencia y la inconsciencia ${ }^{13}$ se reveló más fluida llegando a profundizar en aspectos más ocultos. Como consecuencia, se colocó al inconsciente en el epicentro de la creación. Si volvemos a los conceptos expuestos sobre la concepción de la creación cinematográfica de Dreyer, observamos que el cineasta explicaba la idea de crear desde dentro. Una definición en sintonía con los preceptos del Romanticismo artístico. Como también hemos expuesto, el director danés denominó a este pensamiento abstracción: "concepto creativo que exige que el artista se eleve a partir de la realidad, para

\footnotetext{
${ }^{10}$ Ibid., p. 149.

${ }^{11}$ Ibid., p 149.

12 Ibid., p. 147.

${ }^{13}$ Coleridge, Samuel Taylor (1817): Biographia literaria. Ed. Labor, Barcelona, 1975, p. 58.
} 
reforzar su contenido espiritual, que puede ser psicológico o puramente estético» ${ }^{14}$. Siguiendo sus palabras, entendemos que su idea de la abstracción formula una técnica de creación que representa la parte más íntima del ser humano.

Su concepto sobre la abstracción parece haber conectado las visiones interiores con la idea de espíritu, es decir, el inconsciente con el alma. Si a esto le sumamos su teoría sobre el estilo del artista, hallamos, — siguiendo al cineasta - la fórmula para dotar de alma a las $\operatorname{cosas}^{15}$. Habiendo llegado a este punto, prestemos atención a la definición del pintor romántico Caspar Friedrich sobre la acción de crear:

Cierra tu ojo corporal, con el fin de ver tu imagen, antes de nada, con tu ojo espiritual. Luego conduce hasta la luz del día lo que has visto en las tinieblas, de manera que tal imagen actúe sobre quien la observa desde el exterior hacia el interior. ${ }^{16}$

Esta definición nos traslada al concepto de creación artística que Dreyer ha cultivado en sus trabajos. Siguiendo con este pensamiento, podríamos entonces enunciar que el concepto de abstracción de Carl Th. Dreyer está directamente ligado a los preceptos del Romanticismo. Igualmente, también es posible encontrar una influencia romántica en la obra de Lars von Trier, especialmente al representar el inconsciente del agente Fisher en Forbrydelsens Element. Hecho que tiene como objeto desnaturalizar la verosimilitud que puede proporcionar la imagen visual. Asimismo, esta acción también posibilita al cineasta la exploración del universo interior del ser humano.

Resumiendo, si atendemos a las imágenes en las obras de Dreyer podemos observar una tendencia hacia la simplificación ${ }^{17}$, hacia lo mínimo que representa el color blanco y la luz, especialmente en sus últimos trabajos. Sin embargo, en contraposición, la tendencia en la primera Trilogía de Lars von Trier tiende hacia la oscuridad. Además, el espacio representado por Lars von Trier está cargado de objetos. Sus imágenes componen un cuadro con mucha tensión en el que el fondo se alza por encima de la figura. Ambos cineastas se hallan bajo la influencia de una concepción romántica de la obra artística aunque con muchas diferencias en su puesta en escena.

\section{La hipnosis y el tiempo del inconsciente en Lars von Trier}

La representación del inconsciente que lleva a cabo Lars von Trier en Forbrydelsens Element ha pasado desapercibida en muchos de los estudios que se han realizado sobre su ópera prima. Si profundizamos en la importancia que tiene la elección de la escenificación del inconsciente del protagonista, la recreación de su viaje interior, podríamos enumerar algunos elementos que condicionan a esta obra a tener unas

\footnotetext{
${ }^{14}$ Mont, Ib (1964): op. cit., p. 149.

${ }^{15}$ Ibid., p. 107.

${ }^{16}$ Cita recogida en el libro de Rafael Argullol (1983): Narrar el abismo. Ed. Acantilado, 2006, p. 69. Originaria en: Caspar David Friedrich: Friedrich der Landschaftsmaler zu seinem Gedächtnis. Comentarios de C.G. Carus, Dresde, 1841, p. 19.

${ }^{17}$ Mont, Ib (1964): op. cit., p. 150.
} 
peculiaridades especiales que conectan con una puesta en escena puramente romántica.

- Noche profunda y constante

- Iluminación monocromática amarillenta que ayuda a teñir de irrealidad la escena logrando hacer no familiar lo supuestamente familiar.

- Juegos pronunciados con las perspectivas y las formas

- Repetición de la metáfora de cárceles y escenarios en ruinas

- En el ritmo del film

- Descripciones de pequeños detalles

- Ralentización de la imagen

Este repertorio repetitivo de recursos contribuye a diseñar una atmósfera de irrealidad. Recursos que permiten al cineasta constituir la representación de su idea del inconsciente humano. Rafael Argullol formuló una definición muy detallada sobre la obra de Piranesi acorde con la representación del inconsciente en gran parte de los trabajos de artistas románticos. Reza de la siguiente manera:

Las leyes de la perspectiva renacentista e, incluso, de la «manierista»- son sustituidas por otras nuevas. El ojo deja de tener un lugar central y pierde su percepción omnicomprensiva. Los espacios euclídeos dejan de ser la realidad objetiva, empírica, que domina el mundo de las formas. El reino de la luz se sumerge en el reino de la sombra y del claroscuro. Sujeto y objeto luchan entre sí distanciándose y confundiéndose. ${ }^{18}$

El escritor catalán confiere a la representación piranesiana una visión de lo más interno del ser humano nacida del inconsciente. Por esta razón lo cataloga de atemporal $^{19}$ y enumera puntos básicos, como la anulación de la luz o su sustitución por claroscuros donde priman las sombras. Elementos muy presentes en Forbrydelsens Element.

\section{La hipnosis nos conduce hacia un viaje mental en Forbrydelsens Element}

Haciendo una lectura del proceso hipnótico desarrollado en Forbrydelsens Element, en un primer nivel, observamos una relación entre paciente y terapeuta en un presente que toma lugar instantes antes de ser inducido al trance hipnótico. El tiempo presente tiene una duración en el film de diez minutos. En un segundo nivel, se descubre el viaje mental del detective Fisher regresando mentalmente a su pasado: el terapeuta ha hipnotizado al protagonista con el fin de averiguar qué es lo que le sucedió durante su estancia en Europa hace dos meses. Se inicia por tanto una partida hacia el interior del ser: su inconsciente. La representación de este estado de trance hipnótico propone una marcha especialmente diferente al proceso hipnótico científico común, debido principalmente a que el director lleva la cámara al interior del trance hipnótico. Además, esta travesía por lo ignoto se antoja también especial porque la consciencia del paciente durante la hipnosis parece estar despierta. El protagonista es consciente de lo que sucede: ¿Por qué remarcamos este hecho? Porque el agente Fisher dialoga con el terapeuta y en determinados

\footnotetext{
${ }_{18}^{18}$ Argullol, Rafael (1983): op. cit., p. 37.

${ }^{19}$ Ibid., 38.
} 
momentos no acata sus órdenes; se rebela. El propio director en varias entrevistas ha declarado que este episodio «es una rebelión contra la autoridad»" ${ }^{20}$. La representación de esta situación parece formular una relación a un mismo nivel entre paciente y terapeuta. $\mathrm{O}$, dicho de otra manera, un diálogo entre el pasado hipnótico «abierto» y el presente del terapeuta, que parece eliminar la posición de poder o dominación que suele tener el inductor en el proceso del trance. La escenificación de esta relación inventada carece de verosimilitud. De igual manera, podríamos poner de manifiesto que esta desobediencia de Fisher arroja algo más de luz sobre al género híbrido de ciencia ficción en el cuál es posible inscribir este film.

\section{Diferencias en la utilización del trance hipnótico en la Trilogía de Lars von Trier}

El trance hipnótico narrado en Forbrydelsens Element es dirigido por un terapeuta egipcio que decide aplicar esta técnica con la idea de hallar los motivos por los que el detective de policía Fisher parece sufrir una amnesia transitoria producto de un acontecimiento traumático que experimentó en su último viaje a Europa. El agente no puede recordar qué sucedió durante su estancia en el viejo continente, y su desmemoria le está provocando frecuentes dolores de cabeza que le impiden llevar una vida normal a su regreso. Este hecho, la imposibilidad de llegar a su recuerdo olvidado o reprimido le obsesiona. Su misión se centra en intentar recordar que pasó en ese viaje ${ }^{21}$, como enuncia el terapeuta al comienzo del film y lo define como: «una obsesión Sr. Fisher es un estado de la mente»"

Sin embargo, si nos detenemos en su segundo largometraje, Epidemic (1987), la utilización de la hipnosis difiere ligeramente del resto de films. La regresión que se practica trae consigo la manifestación carnal de la vivencia experimentada. El cineasta realiza una sesión real de hipnosis con un reputado hipnotizador sueco: Svend Ali Hamann. Hamman induce a Gitte Lind a un proceso de regresión. Traslada a la actriz a la Europa del siglo $\mathrm{XIV}^{23}$ donde las devastadoras pandemias causaron la muerte de una tercera parte de la población del continente. Ella se halla en el epicentro de estas epidemias. Gitte comienza a narrar lo que observa a su alrededor. Describe un espacio donde se apilan cadáveres humanos en las calles. Entre ellos, detecta el cuerpo de un niño cubierto por una gran cantidad de ratas. Se acerca al cadáver del infante. Siente que las ratas perciben su presencia y se dirigen hacia ella. La joven danesa rompe a gritos y llantos. Mientras ella se encontraba en trance, Lars von Trier le adhiere a la piel del cuello de Gitte una especie de plástico gelatinoso que simula ser bubas (ganglios linfáticos blandos e inflamados). Una vez hecho esto en el cuerpo de la joven, pide a Hamman que la despierte. Al percatarse de las bubas en su cuerpo ella grita alocadamente.

\footnotetext{
${ }^{20}$ Larsen, Jan Kornun (1984): «A Conversation between Jan Kornun Larsen and Lars von Trier», en Lumholdt, Jan (Ed.) Lars von Trier interviews. Ed. The University Press, USA, 2003, p. 38.

${ }^{21}$ Timecode: 00:01:05.

${ }^{22}$ Timecode: 00:01:22.

${ }^{23}$ Stevenson, Jack (2002): Lars von Trier. Ed. Paidós, Barcelona, 2005, p. 77.
} 

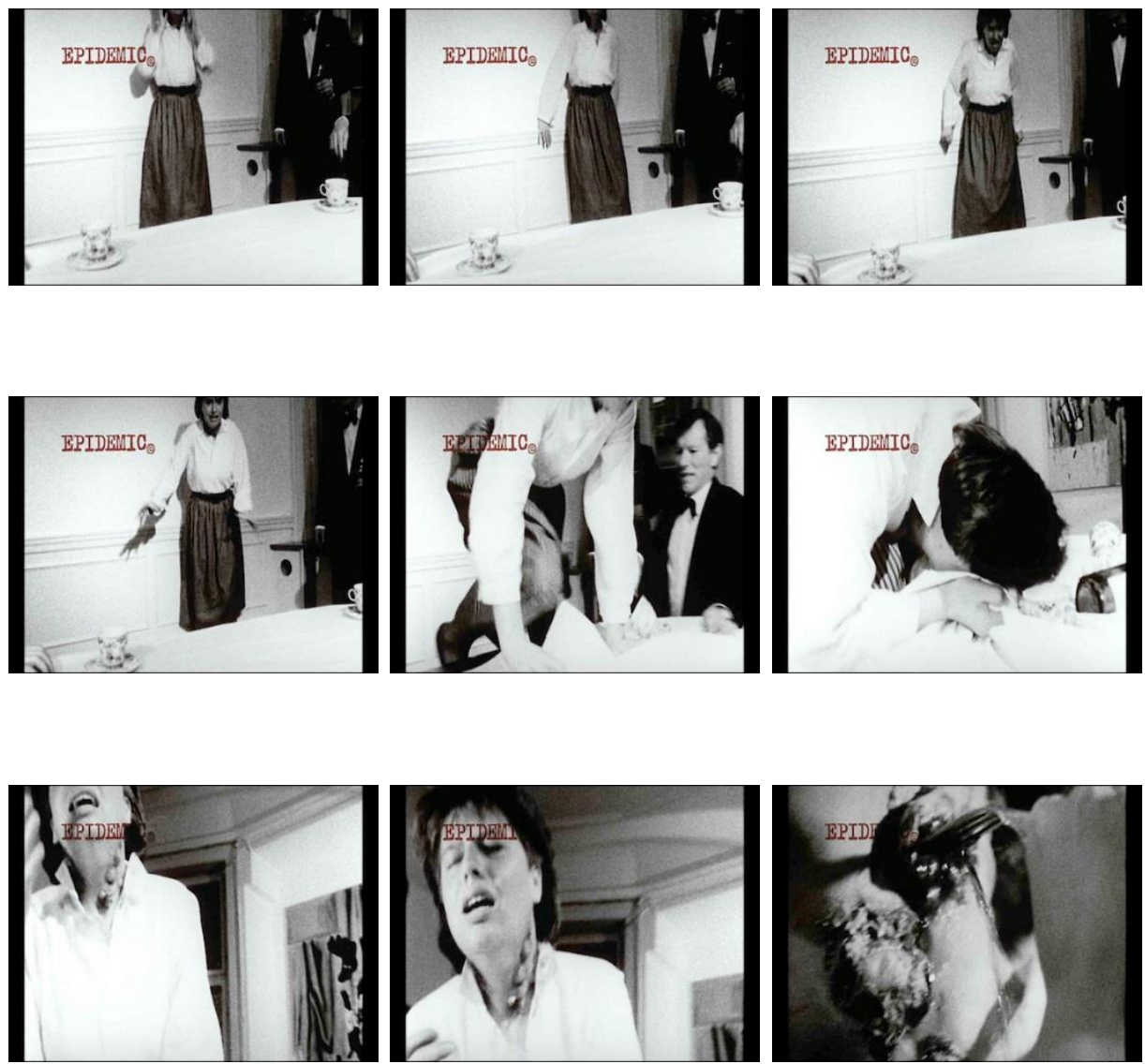

\section{$\left(\right.$ Epidemic $\left.^{24}\right)$}

En este film, a través de la hipnosis, se escenifica el brote psicótico de un personaje que emerge a raíz de creer que ha portado la enfermedad consigo cuando se le ha despertado de la regresión.

Por último, al adentramos en el film Europa (1991), advertimos que comienza con la profunda e hipnótica voz del actor sueco Max von Sydow. Intenta inducirnos al trance hipnótico con el firme propósito de llevarnos a Europa y encerrarnos allí como veremos más adelante.

\section{Max von Sydow (voz en off)}

Ahora escuche mi voz. Mi voz le ayudará y le llevará hacia Europa, cada vez más profundamente. Cada vez que escuche mi voz, con cada palabra y cada número, entrará en un nivel más profundo, más abierto, relajado y receptivo. Ahora voy a contar de uno a diez. Cuando llegue a diez, estará en Europa ${ }^{25}$.

El final de este film es similar a su apertura conformando así una estructura circular. Concluye con la locución en voz en off de Max von Sydow enunciando lo siguiente: «Quiere despertar y liberarse de la imagen de Europa, pero no es posible»"26. Lars

\footnotetext{
${ }^{24}$ Timecode: 01:27:53.

${ }^{25}$ Timecode: 00:00:24.

${ }^{26}$ Timecode: 01:41:01.
} 
von Trier reitera de nuevo la importancia que para él tiene no olvidarse de nuestra propia naturaleza, de lo que somos capaces de hacer.

Por otro lado, es también notorio, especialmente en este largometraje, el uso de la hipnosis como «control» sobre la mente de los otros. Un deseo que se corresponde con una necesidad, como ha manifestado el director en varias entrevistas ${ }^{27}$. Siguiendo con esta idea, habría que señalar que Lars von Trier intenta hipnotizarnos deliberadamente en este film para «implantarnos» una historia. Desea contagiarnos su visión sobre Europa. Una narración sobre nuestro pasado que encierra un fin: apresarnos: "Quiere despertar y liberarse de la imagen de Europa, pero no es posible ${ }^{28}$ —enuncia Max von Sydow. Al final del largometraje nos sentimos cautivos de nuestra propia historia. Éste es el mensaje que el cineasta desea que no olvidemos. Además, lo que descubrimos en Europa es aquello que Fisher en Forbrydelsens Element se encuentra buscando en sus recuerdos inducido por esta técnica. El agente reprimió su pasado durante su viaje al continente europeo y es, el trance hipnótico, la fórmula que posibilita recordar aquello de lo que huía. La hipnosis por tanto permitió liberar -que dejara de reprimir- aquella verdad insoportable: la experiencia de lo siniestro.

\section{Conclusión}

No podemos confirmar que Lars von Trier conociera el método hipnótico a raíz de su familiaridad con los trabajos de Carl Th. Dreyer, pero como hemos expuesto en este artículo, pudiera ser factible esta hipótesis debido a la influencia que tuvo sobre él. Si nos adentramos en el posible significado de del uso de la hipnosis, después de haber analizado esta técnica en su Trilogía, afirmamos que mantiene una clara carga simbólica que desarrollaremos a continuación.

Durante este análisis, hemos comparado el estilo de Dreyer con el de Von Trier. Aunque los dos directores coinciden en buscar la esencia del ser humano con una puesta en escena que mantiene una gran influencia del Romanticismo artístico, la idea de esa esencia, la de lo más básico y puro que late en nuestro interior, no es igual para uno que para otro. Si para Dreyer, la escenificación de lo interior, por ejemplo, en Gertrud, formula la liberación de las posibles convenciones y hábitos de la sociedad, - posibilitando al individuo ser más consciente de su propia unicidad, de su propia alma al formar parte de un todo más grande y orgánico-, para Lars von Trier, la esencia que persigue retratar es la consciencia y aceptación de nuestra naturaleza jupiterina. Siente una terrible fascinación por la destrucción y aniquilación; por la llamada de Tánatos. Y no solo por el hecho en sí, por la acción misma de la catástrofe, sino también por la estética que lo viste. Una fascinación que ha declarado públicamente: «Me fascino por aquello que siempre ha fascinado a la gente, la muerte y otras cosas desagradables" ${ }^{29}$. Y que parece condenarle a llevar a cabo una misión: "mi misión es elevar «lo feo» porque la belleza se encuentra en todas partes» ${ }^{30}$. Aquello que el cineasta danés denomina como «lo feo» está

\footnotetext{
${ }^{27}$ Thomsen, Christian Braad (1996): «Control and chaos», en Lumholdt, Jan (Ed.) Lars von Trier interviews. Ed. The University Press, USA, 2003, p. 109.

${ }^{28}$ Timecode: 01:41:01

${ }^{29}$ Larsen, Jan Kornun (1984): «A Conversation between Jan Kornun Larsen and Lars von Trier», en Lumholdt, Jan (Ed.)... op. cit., p. 41.

${ }^{30}$ Michelsen, Ole (1982): «Passion is lifeblood of Cinema», en Lumholdt, Jan (Ed.),... op. cit., p. 5.
} 
directamente ligado al concepto de lo sublime-terrorífico ${ }^{31}$ que definió Kant influenciado por Burke ${ }^{32}$. En la categoría estética de lo sublime se clasifican símbolos, como: la oscuridad, la desproporción o el terror. Y, en concreto, lo que ha caracterizado a lo sublime-terrorífico ha sido el sentimiento de asombro y de miedo. Entendemos, por tanto, que la puesta en escena en la Trilogía de Lars von Trier mantiene una gran coherencia con aquellos preceptos del Romanticismo que expresan una estética sublime-terrorífica por la que el cineasta, asegurábamos, se siente atraído y que acompaña a lo siniestro representado.

En esta misma dirección, habría que enunciar que la utilización de la hipnosis está cargada de significación. En un primer nivel podemos entender el uso de esta técnica como método para recobrar la verdad oculta —olvidada o reprimida - en el ser humano. Parece recordarnos constantemente que intentar olvidar lo que somos o los pasajes de nuestra historia desencadena un error que se paga caro. De esta manera, al hilo de este pensamiento, las tres tramas de esta Trilogía germinan. Tres personajes humanistas que luchan por el bien de todos, pero su ceguera les impide ver la emergencia de esa verdad en sí mismos o en los otros. La verdad de la que hablamos es aquello que podemos denominar, siguiendo al profesor González Requena, como la emergencia de lo siniestro ${ }^{33}$. Y se visualiza en esta Trilogía de la mano del método hipnótico. Asimismo, la hipnosis como recurso narrativo en la trama permite escenificar en presente aquello que se ha dado en pasado; que ha sucedido. En un segundo nivel, Von Trier no sólo emplea el trance hipnótico como técnica para recordar la experiencia de lo siniestro reprimida, sino que una vez que lo hemos hecho regresar, una vez que lo preso en el inconsciente irrumpe en la consciencia, quedamos atrapados: «... quiere despertar y liberarse de la imagen de Europa, pero no es posible» ${ }^{44}$ — enuncia el narrador al final del film Europa (1991).

En consecuencia, el método hipnótico en la obra del cineasta danés opera como un mecanismo que destapa la representación de la experiencia de lo siniestro. Por un lado, como recurso narrativo, la hipnosis formula una excusa que permite volver escenificar aquello acontecido, pero, por otro, se convierte en un instrumento de poder que le ofrece sobre todo control. La experiencia de lo siniestro ya pasada está condicionada por este ritual simbólico para volverse a repetir. De esta manera, Lars von Trier mantiene al monstruo en su monstruosidad.

\section{Bibliografía}

- Argullol, Rafael (1983): Narrar el abismo. Ed. Acantilado, Barcelona, 2006.

- Björkman, Stig (1999): Trier on von Trier. Ed. Faber and Faber Limited, London, 2003.

\footnotetext{
${ }^{31}$ Kant, Immanuel (1764): Observaciones acerca del sentimiento de lo bello y de lo sublime. Ed. Alianza, Madrid, 2008, p. 32.

${ }^{32}$ Véase Burke, Edmund (1756): De lo sublime y de lo bello. Ed. Alianza, Madrid, 2006.

${ }^{33}$ González Requena, Jesús: «Emergencia de lo siniestro», en Trama\&Fondo, no 2, Madrid, 1997, p. 66.

${ }^{34}$ Timecode: 01:41:01.
} 
- Björkman, Stig y Nyman, Lena (1995): «I Am Curious, Film: Lars von Trier». En Lumholdt, Jan (Ed.) Lars von Trier Interviews. Ed. The University Press of Missisippi, USA, 2003.

- Burke, Edmund (1756): De lo sublime y de lo bello. Ed. Alianza, Madrid, 2006.

- Coleridge, Samuel Taylor (1817): Biographia literaria. Ed. Labor, Barcelona, 1975.

- González Requena, Jesús: «Emergencia de lo siniestro», en Trama\&Fondo, ํㅡㄹ, Madrid, 1997.

- Kant, Immanuel (1764): Observaciones acerca del sentimiento de lo bello y de lo sublime. Ed. Alianza, Madrid, 2008.

- Larsen, Jan Kornun (1984): «A Conversation between Jan Kornun Larsen and Lars von Trier», en Lumholdt, Jan (Ed.) Lars von Trier interviews. Ed. The University Press, USA, 2003.

- Michelsen, Ole (1982): «Passion is lifeblood of Cinema», en Lumholdt, Jan (Ed.) Lars von Trier interviews. Ed. The University Press, USA, 2003.

- Monty, Ib (1964): Carl Th. Dreyer. Sobre el cine. Ed. Gráficas San Martín, Valladolid, 1995.

- Stevenson, Jack (2002): Lars von Trier. Ed. Paidós, Barcelona, 2005.

- Thomsen, Christian Braad (1996): «Control and chaos», en Lumholdt, Jan (Ed.) Lars von Trier interviews. Ed. The University Press, USA, 2003. 